\title{
Возрастные особенности формирования
}

\section{инсулинорезистентности организма}

\section{И ЧУВСТВИТЕАЬНОСТИ К ИНСУАИНУ САИПОЦИТОВ У КРЫС при инАуцированном метаболическом синАроме}

\author{
Н.В. Нарыжная', Ю.Г. Бирулина², Б.К. Курбатов', М.А. Сиротина',
}

\section{ヘ.Н. Маслов ${ }^{1}$}

\author{
${ }^{1}$ Научно-исследовательский институт кардиологии, Томский национальный исследовательский медицинский центр \\ Российской академии наук, \\ 634012, Российская Федерация, Томск, ул. Киевская, 111а
}

${ }^{2}$ Сибирский государственный медицинский университет Министерства здравоохранения Российской Федерации, 634050, Российская Федерация, Томск, Московский тракт, 2

\section{Аннотация}

Пожилой возраст и инсулинорезистентность, сопровождающая метаболический синдром, являются значимыми факторами формирования сердечно-сосудистой патологии.

Цель работы: выявление возрастных особенностей формирования инсулинорезистентности организма и резистентности к инсулину адипоцитов крыс при индуцированном метаболическом синдроме.

Материал и методы. Исследование проведено на крысах-самцах линии Вистар, которые были распределены на следующие группы: 1-я $(n=14)$ - интактные крысы в возрасте 150 дней на момент окончания исследования; 2-я $(n=14)$ - крысы в возрасте 150 дней на момент окончания 90-дневной диеты с высоким содержанием углеводов и жиров (ВУВЖД); 3-я ( $n=14)$ - интактные крысы 540-дневного возраста на момент окончания исследования; 4-я ( $n=$ 14) - крысы в возрасте 540 дней после окончания 90-дневной ВУВЖД. Состав диеты: 16\% белков, 21\% жиров, 46\% углеводов, в том числе $17 \%$ фруктозы, 0,125\% холестерина с заменой питьевой воды 20\%-м раствором фрруктоз. По окончании диеты измеряли массу тела, органов, содержание в сыворотке крови глюкозы, инсулина, триглицеридов, лептина, триглицеридов в печени. Адипоциты эпидидимальной жировой ткани выделяли энзиматически, исследовали содержание активных фрорм кислорода (АФК) с помощью 2,3-дигидродихлорфлуоресцеина диацетата (DCF); выявлено усиление выработки АФК и ингибирование липолиза в ответ на инсулин.

Результаты. Обнаружено, что в обеих возрастных группах при ВУВЖД формируются признаки метаболического синдрома: висцеральное ожирение, гипергликемия, инсулинорезистентность (HOMA-IR), однако в группе молодых крыс более выражены показатели ожирения, в то время как у крыс старшей возрастной группы - признаки инсулинорезистентности. Лептинемия имела прямую корреляционную связь с HOMA-IR $(r S p=0,485 ; p=0,03)$. Инсулинорезистентность адипоцитов наблюдали у крыс старше 540 дней после ВУВЖД.

Заключение. Полученные результаты позволяют говорить о том, что возраст является фрактором риска развития инсулинорезистентности организма; под влиянием возраста происходит снижение чувствительности адипоцитов к инсулину при метаболическом синдроме. Возможным механизмом усугубления инсулинорезистентности с возрастом может быть повышение содержания лептина в сыворотке крови.

Ключевые слова:

Конфликт интересов:

Прозрачность финансовой деятельности: возраст, инсулинорезистентность, метаболический синдром.

авторы заявляют об отсутствии конфликта интересов. Работа выполнена в рамках договора о невозмездном сотрудничестве между НИИ кардиологии Томского НИМЦ и СибГМУ № 01-09/10/117 от 09.07.2020 г.

никто из авторов не имеет финансовой заинтересованности в представленных материалах или методах. Работа выполнена в рамках темы фундаментальных исследований А15-115120910024-0. Разработка методики моделирования индуцированного метаболического синдрома выполнена при фринансовой поддержке Совета по грантам Российской Федерации (МК-143.2020.4).

Нарыжная Наталья Владимировна, e-mail: natalynar@yandex.ru. 
Соответствие принципам этики:

Для цитирования: исследование было одобрено этическим комитетом НИИ кардиологии Томского НИМЦ (протокол № 201 от 30.07.2020 г.).

Нарыжная Н.В., Бирулина Ю.Г., Курбатов Б.К., Сиротина М.А., Маслов Л.Н. Возрастные особенности формирования инсулинорезистентности организма и чувствительности к инсулину адипоцитов у крыс при индуцированном метаболическом синдроме. Сибирский журнал клинической и экспериментальной медицины. 2021;36(3):119-126. https://doi. org/10.29001/2073-8552-2021-36-3-119-126

\title{
Age-related features of developing insulin resistance and adipocyte sensitivity to insulin in rats with induced metabolic syndrome
}

\author{
Natalia V. Naryzhnaya', Yulia G. Birulina², Boris K. Kurbatov', Maria A. Sirotina', \\ Leonid N. Maslov'
}

${ }^{1}$ Cardiology Research Institute, Tomsk National Research Medical Center, Russian Academy of Sciences, 111a, Kievskaya str., Tomsk, 634012, Russian Federation

2 Siberian State Medical University,

2, Moskovsky tract, Tomsk, 634050, Russian Federation

\begin{abstract}
Old age and insulin resistance accompanying metabolic syndrome are significant factors in the development of cardiovascular pathology.

Aim. The aim of the study was to identify the age-related characteristics of developing insulin resistance on the body level and insulin resistance in rat adipocytes in animals with induced metabolic syndrome.

Material and Methods. The study was carried out on male Wistar rats, which were divided into the following groups: group 1 $(n=14)$ comprised intact rats aged 150 days at the end of study; group $2(n=14)$ comprised rats aged 150 days at the end of 90-day period on diet with high contents of carbohydrates and fats (HCHFD); group $3(n=14)$ comprised intact rats aged 540 days at the end of the study; group $4(n=14)$ comprised rats aged 540 days after the end of 90-day HCHFD. Diet composition was as follows: $16 \%$ proteins, $21 \%$ fats, $46 \%$ carbohydrates including $17 \%$ fructose, $0.125 \%$ cholesterol, and replacement of drinking water with a $20 \%$-fructose solution. At the end of the diet, body and organ weights were measured, and contents of glucose, insulin, triglycerides, serum leptin, and liver triglycerides were assessed. Epididymal adipose tissue adipocytes were isolated enzymatically. The content of reactive oxygen species (ROS) was investigated using 2,3-dihydrodichlorofluorescein diacetate. Increased ROS production and lipolysis inhibition in response to insulin were observed.

Results. The signs of metabolic syndrome were observed in both age groups of HCHFD animals and included visceral obesity, hyperglycemia, and insulin resistance measured by homeostatic model assessment of insulin resistance (HOMA-IR). However, the obesity indicators were more pronounced in the group of young rats, whereas the signs of insulin resistance prevailed in older rats. Leptinemia directly correlated with HOMA-IR $(r S p=0.485, p=0.03)$. Insulin resistance of adipocytes was observed in rats older than 540 days after the HCHFD.

Conclusion. The obtained results suggested that age was a risk factor for the development of insulin resistance on the body level. Aging resulted in a decrease in the adipocyte sensitivity to insulin in metabolic syndrome. An increase in leptin may be a possible mechanism for worsening of insulin resistance with age.
\end{abstract}

\section{Keywords:}

Conflict of interest:

Financial disclosure:

Adherence to ethical standards: age, insulin resistance, metabolic syndrome.

the authors do not declare a conflict of interest. The work was carried out within the framework of an agreement on non-commercial cooperation between the Research Institute of Cardiology of the Tomsk National Research Medical Center and the Siberian State Medical University No. 01-09/10/117, 09.07.2020..

no author has a financial or property interest in any material or method mentioned. The work was carried out within the framework of the theme of fundamental research A15-115120910024-0.

the study was approved by the Ethics Committee of Cardiology Research Institute of Tomsk NRMC (protocol No. 201 from 30.07.2020). 

of developing insulin resistance and adipocyte sensitivity to insulin in rats with induced metabolic syndrome. The Siberian Journal of Clinical and Experimental Medicine. 2021;36(3):119-126. https://doi.org/10.29001/2073-8552-2021-36-3-119-126.

\section{Введение}

Избыточный вес и ожирение в настоящее время приравниваются к мировой эпидемии и являются основными фракторами целого ряда метаболических нарушений в органах и тканях, способствующих прогрессированию инсулинорезистентности и развитию метаболического синдрома, увеличивая риск развития сахарного диабета, сердечно-сосудистых заболеваний (ССЗ), гиперлипидемии [1]. Распространенность метаболического синдрома и его компонентов значительно возросла за последние десятилетия, став проблемой общественного здравоохранения. Частота встречаемости метаболического синдрома колеблется от 7,5 до $42,2 \%$ в разных странах [2], что связывают с возросшими нездоровыми привычками и малоподвижным образом жизни. Одним из патогенетических фракторов, опосредующих увеличение риска ССЗ при метаболическом синдроме, является инсулинорезистентность [3]. В последние годы получено достаточно доказательств, подтверждающих связь гипертрофии клеток жировой ткани, дисбаланса выработки адипокинов с формированием сердечно-сосудистой патологии [4, 5]. Вместе с тем вопрос инсулинорезистентности адипоцитов, формирующейся при метаболическом синдроме, остается открытым.

Вторым, не менее значимым фактором, приводящим к росту заболеваемости ССЗ, является старение, которое снижает толерантность пациентов к ишемии, оказывает значительное влияние на прогноз заболевания [6]. У пожилых пациентов формируются структурные и функциональные изменения сердечно-сосудистой системы, которые имеют прямую связь с увеличением частоты ССЗ [7]. Инсулинорезистентность и артериальное давление прогрессивно возрастают у пациентов старшей возрастной группы $[8,9]$. Несмотря на то, что исследования последних лет показывают снижение роли метаболического синдрома как фактора риска ССЗ у пациентов старше 80 лет [10], фактор возраста должен учитываться в совокупности с наличием метаболического синдрома. Показано, что индуцированный метаболический синдром усугубляет сосудистое старение и развитие возрастной артериальной гипертензии у крыс [11].

Цель настоящей работы: выявление возрастных особенностей формирования резистентности к инсулину адипоцитов крыс при индуцированном метаболическом синдроме.

\section{Материал и методы}

Исследование было проведено на крысах-самцах линии Вистар в возрасте 60 дней, вес которых в начале исследования составлял 350-400 г, и в возрасте 450 дней весом 400-600 г в начале эксперимента. Все процедуры соответствовали Директиве Европейского парламента 2010/63 / EU и Заявлению FASEB о принципах использования животных в исследованиях и образовании. Исследование было одобрено этическим комитетом НИИ кардиологии Томского НИМЦ (протокол № 201 от 30.07.2020 г.).

Диета с высоким содержанием углеводов и высоким содержанием жиров (ВУВЖД, 90 дней) включала 16\% белков, 21\% жиров, 46\% углеводов, в том числе 17\% фрруктозы, 0,125\% холестерина [12]. Вода была заменена 20\%-м раствором фруктозы. Крысам контрольной группы давали стандартный корм для грызунов (24\% белков, 6\% жиров, 44\% углеводов) и чистую воду ad libitum.

Экспериментальные группы распределялись следующим образом: 1-я $(n=14)$ - интактные крысы в возрасте 150 дней на момент окончания исследования (стандартный рацион); 2-я ( $n=14)$ - крысы в возрасте 150 дней на момент окончания 90-дневной диеты с высоким содержанием углеводов и жиров (ВУВЖД); 3-я $(n=14)$ - интактные крысы 540-дневного возраста на момент окончания исследования (стандартный рацион); 4-я $(n=12)-$ крысы в возрасте 540 дней после окончания 90-дневной ВУВЖД.

После окончания кормления ВУВЖД животных содержали в течение 1 нед. на стандартной диете и обычной питьевой воде, чтобы исключить осмотический компонент увеличения объема крови из-за потребления фрруктозы.

Животных выводили из эксперимента с предварительной анестезией хлоралозой (100 мг/кг внутрибрюшинно). Перед забоем забирали образцы крови из общей сонной артерии. Извлекали и взвешивали миокард, почки, брюшной и эпидидимальный жир (ЭпЖТ), отбирали и замораживали в жидком азоте образцы ткани печени для биохимического исследования.

Образцы крови центрифугировали 15 мин при $3000 \mathrm{~g}$ замораживали и хранили при $-70{ }^{\circ} \mathrm{C}$. Определяли глюкозу и триацилглицериды в сыворотке крови ферментативным колориметрическим методом с помощью наборов (В-8054, В-8322, «Вектор-Бест», Новосибирск, Россия), инсулин (ab100578, Abcam) и лептин (SEA084Ra CloudClone, USA) методом ELISA. Образцы измеряли с помощью микропланшетного ридера Infinite 200 PRO (Tecan $\mathrm{GmbH}$, Зальцбург, Австрия). Гомеостатическую модель оценки инсулинорезистентности (HOMA-IR) рассчитывали следующим образом: сывороточный инсулин × сывороточная глюкоза / 22,5.

Образцы ткани печени (250 мг) гомогенизировали в жидком азоте, фракцию липидов экстрагировали в 1 мл смеси хлороформ : метанол (2: 1) [13].

Фракцию хлороформа собирали и добавляли 20 мкл 20\%-го раствора тизита (Sigma-Aldrich, США) в хлороформе для эмульгирования липидов [14]. Фракцию хлороформа упаривали в потоке $\mathrm{N} 2$, осадок растворяли в деионизированной воде и определяли триацилглицериды так же, как в сыворотке. Содержание триацилглицеридов в печени выражали в мг/г ткани.

Выделение адипоцитов проводили энзиматически, стерильно в ламинарном шкафу II класса защиты (БАВп-01-«Ламинар-с»-1,5, ЗАО «Ламинарные системы», Миасс, Россия) [15]. ЭпЖТ массой 1-1,5 гополаскивали солевым раствором, измельчали, инкубировали 35-40 мин при температуре $37^{\circ} \mathrm{C}$ и постоянном мягком перемешивании (10 об./мин) в 5 мл стерильного раствора коллагеназы I типа («ПанЭко», Россия) 1 мг/мл в буфрере Кребса - Рингера (2 mM D-глюкозы, 135 mM NaCl, 2,2 mM 


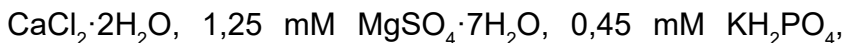
2,17 $\mathrm{mM} \mathrm{Na}_{2} \mathrm{HPO}_{4}, 25 \mathrm{mM}$ HEPES, 3,5\% BSA, 0,2 mM аденозина). Для нейтрализации коллагеназы добавляли буфер Кребса - Рингера в соотношении $1: 1$. Клеточную суспензию фильтровали через нейлоновый фильтр (Falcon ${ }^{\text {TM }}$ Cell strainer, диаметр пор 100 мкм) и трехкратно промывали теплым буфрером Кребса - Рингера.

Жизнеспособность культуры адипоцитов верифицировали при окраске Hoechst 33,342 (Invitrogen, 5 мкг/мл, окрашивает ядра жизнеспособных клеток) и пропидиум йодидом (Sigma-Aldrich, 10 мкг/мл, окрашивает ядра мертвых клеток) на флуоресцентном микроскопе Ахіо Observer.Z1 (Carl Zeiss Surgical $\mathrm{GmbH}$, Oberkochen, Germany) [16]. Культура с жизнеспособностью ниже 90\% исключалась из исследования. Образцы остальных клеток существенно не различались по процентному содержанию жизнеспособных клеток.

Чувствительность адипоцитов к инсулину оценивали по увеличению продукции активных форм кислорода (инсулинозависимая генерация АФК) [17] и по ингибированию липолиза в ответ на добавление инсулина в инкубационную среду $[18,19]$. В первом случае адипоциты в 200 мкл буфера Кребса - Рингера (1,25 × 106 клеток/мл) добавляли в две лунки 96-луночного планшета (5*105 клеток на лунку) и инкубировали в течение 30 мин в присутствии 125 мкМ 2,3-дигидродихлорфлуоресцеина диацетата (DCF-DA) в микропланшетном ридере (INFINITE 200M; Tecan, Grödig, Австрия) при $37^{\circ} \mathrm{C}$ для внутриклеточного поглощения и деэтерификации DCF-DA до DCF в жизнеспособных адипоцитах. Начальную флуоресценцию DCF измеряли при длине волны $\lambda e x=500 \mathrm{HM}, \lambda e \mathrm{e}=530 \mathrm{Hм}$. В одну из двух лунок добавляли 20 нМ инсулина, адипоциты инкубировали в течение 120 мин при $37^{\circ} \mathrm{C}$ и измеряли фллуоресценцию, как описано выше. Оценивали увеличение флуоресценции относительно исходных значений и увеличение прироста под действием инсулина. Накопление активных форм кислорода адипоцитами верифицировали микроскопически. Клеточную среду после 120 мин инкубации адипоцитов в предыдущем методе собирали и использовали для изучения ингибирования липолиза инсулином. Среду обезжиривали реакцией Фолча [13], глицерин определяли с помощью набора EGLY-200 (Gentaur).

Статистическую обработку данных проводили с использованием программы STATISTICA 13.0 (StatSoft, Inc.). Полученные данные проверялись на согласие с нормальным законом распределения с помощью критерия Шапиро - Уилка. Данные, соответствующие нормальному распределению (масса тела, масса миокарда, почек, брюшного жира, ЭпЖТ), представлены средним и стандартным отклонением $(M \pm S D)$. Данные, не соответствующие нормальному закону распределения (глюкоза, инсулин, HOMA-IR, триглицериды сыворотки крови и печени, лептин, размер адипоцита, возрастание АФК в ответ на воздействие инсулина, снижение липолиза в ответ на воздействие инсулина), представлены в виде медианы $(M е)$ и межквартильного интервала (Q25; Q75). Проверку на гомогенность дисперсий производили с использованием критерия Ливиня (Levene). При сравнении нескольких независимых нормальных выборок количественных данных использовали двухфакторный дисперсионный анализ (two-way ANOVA) c последующим применением критерия Тьюки для апостериорных сравнений показателей с гомогенными дисперсиями, в противном случае, критерий Краскела - Уоллиса с апостериорными сравнениями по критерию Манна - Уитни. Для выявления связи между параметрами применяли коэфффициент ранговой корреляции Спирмена ( $r \mathrm{Sp})$. Пороговое значение уровня значимости р было принято равным 0,05.

Работа выполнена с применением оборудования Центра коллективного пользования «Медицинская геномика».

\section{Результаты}

ВУВЖД в течение 90 дней приводила к увеличению массы тела у молодых крыс, у старых крыс не наблюдалось статистически значимого увеличения массы тела относительно соответствующего возрастного контроля (табл. 1).

Таблица 1. Масса животных и масса органов крыс различных возрастных групп при содержании на диету с высоким содержанием углеводов и жиров, г, $M \pm S D$

Table 1. Body weight and organ weight, $M \pm S D$

\begin{tabular}{|c|c|c|c|c|}
\hline $\begin{array}{l}\text { Macca, r } \\
\text { Weight, g }\end{array}$ & $\begin{array}{c}\text { 1-я группа (интактные крысы } \\
\text { 150-дневного возраста) } \\
\text { Group } 1 \text { (naïve 150-day-old } \\
\text { rats) }\end{array}$ & $\begin{array}{c}\text { 2-я группа (крысы 150-дневного } \\
\text { возраста с ВУВЖД) } \\
\text { Group } 2 \text { (150-day-old rats after } \\
\text { HCHFD) }\end{array}$ & $\begin{array}{c}\text { 3-я группа (интактные крысы } \\
\text { 540-дневного возраста) } \\
\text { Group } 3 \text { (naïve 540-day-old } \\
\text { rats) }\end{array}$ & $\begin{array}{c}\text { 4-я группа } \\
\text { (крысы 540-дневного } \\
\text { возраста с ВУВЖД) } \\
\text { Group } 4 \text { (540-day-old rats } \\
\text { after HCHFD) }\end{array}$ \\
\hline $\begin{array}{l}\text { Тело } \\
\text { Body }\end{array}$ & $430,3 \pm 20,5$ & $\begin{array}{c}481,2 \pm 47,9 \\
p_{1-2}=0,017\end{array}$ & $\begin{array}{l}517,3 \pm 48,5 \\
p_{1-3}<0,001\end{array}$ & $\begin{array}{l}520,0 \pm 121,1 \\
p_{1-4}=0,0044\end{array}$ \\
\hline $\begin{array}{l}\text { Миокард } \\
\text { Мyocardium }\end{array}$ & $1,39 \pm 0,37$ & $1,31 \pm 0,20$ & $\begin{array}{c}1,54 \pm 0,16 \\
p_{1-3}=0,029 \\
p_{2-3}=0,0051\end{array}$ & $1,44 \pm 0,20$ \\
\hline $\begin{array}{l}\text { Почки } \\
\text { Kidneys }\end{array}$ & $2,8 \pm 0,21$ & $2,8 \pm 0,30$ & $\begin{array}{l}3,51 \pm 0,59 \\
p_{1-3}=0,0008 \\
p_{2-3}=0,0009\end{array}$ & $\begin{array}{c}3,05 \pm 0,63 \\
p_{3-4} \text { n.s. }\end{array}$ \\
\hline $\begin{array}{l}\text { Брюшной жир } \\
\text { Abdominal fat }\end{array}$ & $8,32 \pm 4,32$ & $\begin{array}{c}16,{ }_{46 \pm 6,00} \\
p_{1-2}=0,0014\end{array}$ & $9,91 \pm 3,67$ & $\begin{array}{c}17,47 \pm 12,67 \\
p_{1-4}=0,01 \\
p_{3-4}=0,049\end{array}$ \\
\hline $\begin{array}{l}\text { Эпидидимальный жир } \\
\text { Epididymal fat }\end{array}$ & $4,06 \pm 0,86$ & $\begin{array}{l}5,47 \pm 1,07 \\
p_{1-2}=0,01\end{array}$ & $3,79 \pm 0,91$ & $\begin{array}{c}4,27 \pm 1,94 \\
p_{3-4} \text { n.s. }\end{array}$ \\
\hline
\end{tabular}

Примечание: здесь и в табл. 2: $p$ - значимость различий по сравнению с соответствующей группой; критерий Краскела - Уоллиса (данные не удовлетворяют условию равенства групповых дисперсий); $p$ - two-way ANOVA с последующей процедурой множественного сравнения, критерий Тьюки (данные удовлетворяют условию равенства групповых дисперсий).

Note: here and in Table 2: $p$ - significance of differences in comparison with the corresponding group; Kruskal - Wallis test (data do not satisfy the condition of equality of group variances); $p$ - two-way ANOVA followed by a multiple comparison procedure, Tukey's test (data satisfy the condition of equality of group variances). 
ВУВЖД способствовала увеличению массы брюшного жира в обеих возрастных группах, однако увеличение массы ЭпЖТ под действием ВУВЖД происходило только у молодых крыс (см. табл. 1). ВУВЖД не приводила к увеличению массы миокарда или почек относительного соответствующего возрастного контроля в группах молодых крыс и крыс возраста 540 дней.

ВУВЖД приводила к увеличению уровня глюкозы в сыворотке крови крыс обеих возрастных групп (табл. 2). Статистически значимое повышение содержания инсулина в сыворотке крови наблюдалось только в группе старых крыс. Таким образом, интегральный индекс HOMA-IR под влиянием ВУВЖД увеличился в обеих возрастных группах (см. табл. 2), однако у старых крыс наблюдался более высокий HOMA-IR. Содержание триглицеридов в печени увеличивалось под влиянием диеты в обеих возрастных группах. По уровню триацилглицеридов сыворотки между группами различий не выявлено. Содержание лептина в сыворотке крови под влиянием ВУВЖД возрастало в обеих возрастных группах, однако в группе крыс старше 540 дней этот показатель был значимо выше, чем у молодых крыс. Корреляционный анализ показал прямую корреляционную связь между HOMA-IR и содержанием лептина в сыворотке крови ( $r \mathrm{Sp}=0,485, p=0,03$; рис. 1$)$.

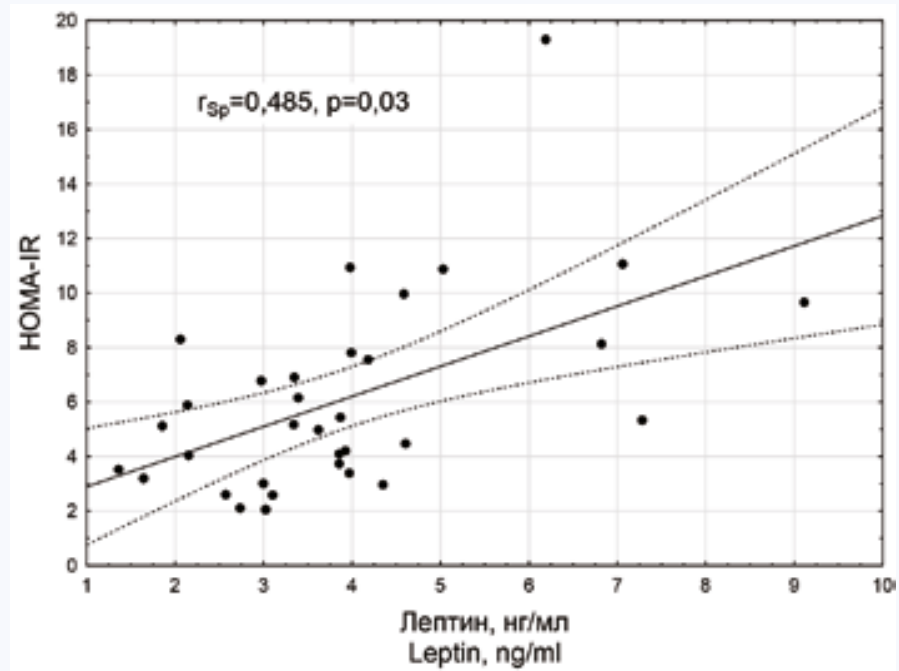

Рис. 1. Зависимость выраженности инсулинорезистентности от содержания лептина в сыворотке крови крыс различных возрастных групп с индуцированным метаболическим синдромом

Примечание: $r_{\mathrm{Sp}}$ - коэффициент корреляции Спирмена, HOMA-IR - гомеостатическая модель оценки инсулинорезистентности (Нотеоstatic Моdel Assessment of Insulin Resistance).

Fig. 1. Relationship of insulin resistance severity with the serum level of leptin in rats with induced metabolic syndrome in different age groups Note: $r \mathrm{Sp}$ - Spearman's correlation coefficient. HOMA-IR - homeostatic model assessment of insulin resistance.

Таблица 2. Биохимические параметры, $M \pm S D$

Table 2. Biochemical parameters, $M \pm S D$

\begin{tabular}{|c|c|c|c|c|}
\hline $\begin{array}{l}\text { Параметры } \\
\text { Parameters }\end{array}$ & $\begin{array}{c}\text { 1-я группа (интактные } \\
\text { крысы 150-дневного } \\
\text { возраста) } \\
\text { Group } 1 \\
\text { (naïve 150-day-old rats) }\end{array}$ & $\begin{array}{c}\text { 2-я группа } \\
\text { (крысы 150-дневного } \\
\text { возраста с ВУВЖД) } \\
\text { Group } 2 \\
\text { (150-day-old rats after } \\
\text { HCHFD) }\end{array}$ & $\begin{array}{c}\text { 3-я группа (интактные } \\
\text { крысы 540-дневного } \\
\text { возраста) } \\
\text { Group } 3 \\
\text { (Naïve 540-day-old rats) }\end{array}$ & $\begin{array}{c}\text { 4-я группа } \\
\text { (крысы 540-дневного } \\
\text { возраста с ВУВЖД) } \\
\text { Group } 4 \\
\text { (540-day-old rats after } \\
\text { HCHFD) }\end{array}$ \\
\hline $\begin{array}{l}\text { Глюкоза, мМ/л } \\
\text { Fasting serum glucose, } \mathrm{mmol} / \mathrm{L}\end{array}$ & $5,25(4,9 ; 5,9)$ & $\begin{array}{c}7,3(6,8 ; 7,8) \\
p_{1-2}<0,001\end{array}$ & $6,1(5,7 ; 6,3)$ & $\begin{array}{l}7,7(7,3 ; 8,3) \\
p_{1-4}<0,001 \\
p_{3-4}=0,006\end{array}$ \\
\hline $\begin{array}{l}\text { Инсулин, } п \mathrm{M} / л \\
\text { Fasting serum insulin, pmol/L }\end{array}$ & $12,0(10,5 ; 13,5)$ & $\begin{array}{c}17,6(15,7 ; 22,8) \\
p_{1-2}>0,05\end{array}$ & $17,7(16,2 ; 25,1)$ & $\begin{array}{c}26,0(22,0 ; 32,0) \\
p_{1-4}<0,001\end{array}$ \\
\hline HOMA-IR & $2,81(2,34 ; 3,36)$ & $\begin{array}{c}5,44(5,17 ; 7,91) \\
p_{1-2}=0,015\end{array}$ & $\begin{array}{c}4,98 \\
(4,10 ; 6,91)\end{array}$ & $\begin{array}{c}8,90 \\
(7,30 ; 10,45) \\
p_{1-4}<0,001 \\
p_{2-4}=0,045\end{array}$ \\
\hline $\begin{array}{l}\text { Триглицериды сыворотки крови, мМ/л } \\
\text { Serum triacylglyceride, } \mathrm{mmol} / \mathrm{L}\end{array}$ & $\begin{array}{c}1,01 \\
(0,87 ; 1,57) \\
\end{array}$ & $\begin{array}{c}1,04 \\
(0,87 ; 1,41) \\
\end{array}$ & $\begin{array}{c}1,12 \\
(0,86 ; 1,31) \\
\end{array}$ & $\begin{array}{c}0,83 \\
(0,73 ; 1,41)\end{array}$ \\
\hline $\begin{array}{l}\text { Триглицериды печени, мг/г } \\
\text { Liver triacylglycerides, } \mathrm{mg} / \mathrm{g}\end{array}$ & $\begin{array}{c}8,1 \\
(7,3 ; 10,0)\end{array}$ & $\begin{array}{c}15,28 \\
(13,9 ; 27,6) \\
p_{1-2}=0,002\end{array}$ & $\begin{array}{c}11,86 \\
(10,9 ; 15,4)\end{array}$ & $\begin{array}{c}14,93 \\
(11,0 ; 33,0) \\
p_{1-4}<0,005 \\
p_{3-4}=0,04\end{array}$ \\
\hline $\begin{array}{l}\text { Лептин, нг/мл } \\
\text { Leptin, ng/mL }\end{array}$ & $\begin{array}{c}3,00 \\
(1,91 ; 3,63)\end{array}$ & $\begin{array}{c}3,92 \\
(3,60 ; 5,61) \\
p_{1-2} \text { n.s. }\end{array}$ & $\begin{array}{c}3,48 \\
(2,15 ; 3,92) \\
p_{1-3} \text { n.s. }\end{array}$ & $\begin{array}{c}4,29 \\
(3,58 ; 7,06) \\
p_{1-4}=0,003 \\
p_{3-4}=0,014\end{array}$ \\
\hline
\end{tabular}


Средний размер адипоцита ЭпЖТ крыс возрастом 150 дней составил 82,26\%, у крыс возрастом 540 дней 83,37 мкм. В результате ВУВЖД статистически значимого увеличения размера адипоцитов ЭпЖТ не происходило в обеих возрастных группах (табл. 3).

Содержание активных фрорм кислорода в адипоцитах ЭпЖТ не различалась в группах (данные не приведены в таблице). Однако в ответ на воздействие инсулина про- исходило возрастание АФК адипоцитов только в группах молодых крыс, что свидетельствует об их реакции на инсулин. Кроме того, инсулин вызывал снижение липолиза в группах молодых крыс, как содержащихся на стандартном рационе, так и на ВУВЖД. В группе крыс возрастом 540 дней после применения ВУВЖД наблюдали отсутствие реакции снижения липолиза в ответ на воздействие инсулина (см. табл. 3).

Таблица 3. Размер адипоцитов эпидидимальной жировой ткани и реакция адипоцитов на инсулин, $M \pm S D$ Table 3. Size of epididymal adipocytes and adipocyte response to insulin, $M \pm S D$

\begin{tabular}{|c|c|c|c|c|}
\hline Группы & $n$ & $\begin{array}{c}\text { Размер } \\
\text { адипоцита, мкм } \\
\text { Adipocyte size, } \\
\mu \mathrm{m}\end{array}$ & $\begin{array}{c}\text { Возрастание АФК в ответ на } \\
\text { воздействие инсулина, усл. ед. } \\
\text { Insulin-dependent ROS genera- } \\
\text { tion in adipocytes, a.u. }\end{array}$ & $\begin{array}{c}\text { Снижение липолиза в ответ на } \\
\text { воздействие инсулина, усл. ед. } \\
\text { Insulin-dependent inhibition of } \\
\text { lipolysis, a.u. }\end{array}$ \\
\hline $\begin{array}{l}\text { 1-я группа (интактные крысы } 150 \text {-дневного возраста) } \\
\text { Group } 1 \text { (naïve } 150 \text {-day-old rats) }\end{array}$ & 15 & $\begin{array}{c}82,25 \\
(76,20 ; 89,60)\end{array}$ & $1,23(0,87 ; 1,49)$ & $1,19(1,03 ; 1,36)$ \\
\hline $\begin{array}{l}\text { 2-я группа (крысы 150-дневного возраста с ВУВжД) } \\
\text { Group } 2 \text { (150-day-old rats after HCHFD) }\end{array}$ & 15 & $\begin{array}{c}92,36 \\
(88,73 ; 94,25) \\
p_{1-2}=0,031\end{array}$ & $\begin{array}{c}1,48(1,17 ; 1,86) \\
p_{1}>0,05\end{array}$ & $1,21(1,07 ; 1,30)$ \\
\hline $\begin{array}{l}\text { 3-я группа (интактные крысы 540-дневного возраста) } \\
\text { Group } 3 \text { (Naïve 540-day-old rats) }\end{array}$ & 14 & $\begin{array}{c}83,37 \\
(80,31 ; 88,17)\end{array}$ & $0,83(0,67 ; 0,92)$ & $1,31(1,23 ; 1,36)$ \\
\hline $\begin{array}{l}\text { 4-я группа (крысы 540-дневного возраста с ВУВжД) } \\
\text { Group } 4 \text { (540-day-old rats after HCHFD) }\end{array}$ & 12 & $\begin{array}{c}83,31 \\
(75,93 ; 98,72)\end{array}$ & $\begin{array}{c}0,78(0,40 ; 0,98) \\
p_{1-4}=0,046 \\
p_{2-4}=0,007\end{array}$ & $\begin{array}{c}1,11(1,09 ; 1,19) \\
p_{3-4}=0,05\end{array}$ \\
\hline
\end{tabular}

Примечание: АФК - активные формы кислорода, $p$ - значимость различий по сравнению с соответствующей группой, критерий Краскела - Уоллиса и критерий Манна - Уитни для апостериорных парных сравнений.

Note: ROS - reactive oxygen spices, $p$ - significance of differences compared with the corresponding group, the Kruskal - Wallis test, Mann - Whitney test (data do not satisfy the condition of equality of variances).

\section{Обсуждение}

Результаты проведенного исследования показали, что ВУВЖД (так называемая «диета кафетерия») приводила к увеличению массы тела у молодых, но не у старых крыс. У старых крыс наблюдалось только увеличение массы абдоминального жира, то есть висцеральное ожирение. После ВУВЖД у молодых и старых крыс было обнаружено нарушение углеводного обмена, при этом в группе молодых крыс оказалось повышено содержание глюкозы, а у старых крыс повысились уровни как глюкозы, так и инсулина. В результате ВУВЖД индекс инсулинорезистентности HOMA-IR увеличивался у старых крыс больше, чем у молодых животных. Таким образом, полученные результаты показывают, что метаболический синдром формируется в обеих возрастных группах. Об этом свидетельствует увеличение массы тела, массы жировой ткани, инсулинорезистентность и накопление триглицеридов в печени. Однако ожирение наиболее выражено в группе молодых крыс после ВУВЖД, в то время как инсулинорезистентность у старых крыс. В целом данные о формировании метаболического синдрома в результате применения ВУВЖД у крыс линии Вистар согласуются с ранее опубликованными $[20,21]$. Вместе с тем данные, свидетельствующие о влиянии возраста на формирование инсулинорезистентности в результате диеты, получены впервые.

Исследование изолированных адипоцитов подтвердило гипотезу о более выраженной инсулинорезистентности в группе молодых крыс при ВУВЖД. Так, снижение реакции адипоцитов на инсулин было обнаружено только у старых крыс после ВУВЖД. Этот факт может говорить в пользу того, что возраст является фактором риска развития инсулинорезистентности адипоцитов при метабо- лическом синдроме. В последние годы многочисленные исследования подтвердили важную роль инсулинорезистентности в развитии метаболических и сердечно-сосудистых осложнений даже у пациентов без диабета 2-го типа [22].

В качестве механизма влияния инсулинорезистентности жировой ткани на формирование сердечно-сосудистой патологии можно предположить дисбаланс выброса адипоцитокинов. Исследованиями последних лет продемонстрирована связь повышенного уровня лептина с риском развития ишемической болезни сердца [23]. В нашем исследовании обнаружено, что в результате ВУВЖД формируется лептинемия, более выраженная в старшей возрастной группе. Наличие прямой корреляционной связи между уровнем лептина и инсулинорезистентностью может служить косвенным доказательством вовлечения лептина в патогенез инсулинорезистентности при ВУВЖД. Единичные исследования показали возрастную гиперлипидемию, что, как полагают авторы, приводит к нарастанию резистентности к лептину с возрастом [24]. Полученные данные позволяют выдвинуть гипотезу о формировании функциональных нарушений адипоцитов без их гипертрофии в пожилом возрасте. Однако это предположение требует подтверждения и будет являться предметом наших исследований в будущем.

\section{Заключение}

Полученные результаты позволяют говорить о том, что возраст является фактором риска развития инсулинорезистентности адипоцитов и организма в целом при метаболическом синдроме. Возможным механизмом усугубления инсулинорезистентности с возрастом может быть увеличение содержания лептина. 


\section{Литература / References}

1. Katsimardou A., Imprialos K., Stavropoulos K., Sachinidis A., Doumas M., Athyros V. Hypertension in metabolic syndrome: Novel insights. Curr. Hypertens. Rev. 2020;16(1):12-18. DOI: 10.2174/157340211566 6190415161813.

2. Gouveia É.R., Gouveia B.R., Marques A., Peralta M., França C., Lima A. et al. Predictors of metabolic syndrome in adults and older adults from Amazonas. Brazil. Int. J. Environ. Res. Public Health. 2021;18(3):1303. DOI: 10.3390/ijerph18031303.

3. Reaven G.M. Insulin resistance: The link between obesity and cardiovascular disease. Endocrinol. Metab. Clin. North. Am. 2008;37(3):581601. DOI: 10.1016/j.ecl.2008.06.005.

4. Kou H., Deng J., Gao D., Song A., Han Z., Wei J. et al. Relationship among adiponectin insulin resistance and atherosclerosis in non-diabetic hypertensive patients and healthy adults. Clin. Exp. Hypertens 2018;40(7):656-663. DOI: 10.1080/10641963.2018.1425414.

5. Naryzhnaya N.V., Koshelskaya O.A., Kologrivova I.V., Kharitonova O.A., Evtushenko V.V., Boshchenko A.A. Hypertrophy and insulin resistance of epicardial adipose tissue adipocytes: Association with the coronary artery disease severity. Biomedicines. 2021;9(1):64. DOI: 10.3390/biomedicines9010064.

6. Tofler G.H., Muller J.E., Stone P.H., Willich S.N., Davis V.G., Poole W.K. et al. Factors leading to shorter survival after acute myocardial infarction in patients ages 65 to 75 years compared with younger patients. Am. $J$. Cardiol. 1988;62(13):860-867. DOI: 10.1016/0002-9149(88)90882-X.

7. Strait J.B., Lakatta E.G. Aging-associated cardiovascular changes and their relationship to heart failure. Heart Fail. Clin. 2012;8(1):143-164. DOI: 10.1016/j.hfc.2011.08.011.

8. Avolio A.P., Kuznetsova T., Heyndrickx G.R., Kerkhof P.L.M., Li J.K.-J. Arterial flow, pulse pressure and pulse wave velocity in men and women at various ages. In: Advances in experimental medicine and biology. New York: Springer LLC; 2018;1065:153-168. DOI: 10.1007/978-3-319-77932-4 10.

9. Strazhesko I.D., Kashtanova D.A., Dudinskaya E.N., Tkacheva O.N. Arterial aging: The role of hormonal and metabolic status and telomere biology. In: Biomarkers of human aging; Moskalev A. (ed.). New York: Springer, Cham; 2019;10:329-348. DOI: 10.1007/978-3-030-24970-0_20.

10. Lind L., Sundström J., Ärnlöv J., Risérus U., Lampa E. A longitudinal study over 40 years to study the metabolic syndrome as a risk factor for cardiovascular diseases. Sci. Rep. 2021;11(1):2978. DOI: 10.1038/ s41598-021-82398-8.

11. Naryzhnaya N., Kurbatov B., Gorbunov A., Derkachev I., Logvinov S. Birulina J. et al. High carbohydrate high fat diet induces the production of connective tissue growth factors, increased blood pressure, and changes in the aortic wall in aged rats. FASEB J. 2021;35:S1.05125. DOI: 10.1096/fasebj.2021.35.S1.05125.

12. Бирулина Ю.Г., Иванов В.В., Буйко В.В., Быков В.В., Смаглий Л.В., Носарев А.В. и др. Экспериментальная модель метаболического синдрома у крыс на основе высокожировой и высокоуглеводной диеты. Бюллетень сибирской медицины. 2020;19(4):14-20. DOI: 10.20538/1682-0363-2020-4-14-20.

\section{Информация о вкладе авторов}

Нарыжная Н.В. - разработка концепции и дизайна исследования проведение исследования, подготовка текста статьи, обоснование рукописи, проверка критически важного интеллектуального содержания.

Бирулина Ю.Г. - разработка концепции исследования, разработка модели индуцированного метаболического синдрома, подготовка текста статьи.

Курбатов Б.К. - разработка дизайна исследования, проведение исследования, статистический анализ и интерпретация данных, подготовка текста статьи.

Сиротина М.А - проведение исследования, подготовка текста статьи.

Маслов Л.Н. - разработка концепции, подготовка текста статьи, обоснование рукописи, проверка критически важного интеллектуального содержания и окончательное утверждение рукописи для публикации.

\section{Сведения об авторах}

Нарыжная Наталья Владимировна, д-р мед. наук, ведущий научный сотрудник, лаборатория экспериментальной кардиологии, Науч-
Birulina Yu.G., Ivanov V.V., Buyko E.E., Bykov V.V., Smagliy L.V., Nosarev A.V. et al. High-fat, high-carbohydrate diet-induced experimental model of metabolic syndrome in rats. Bulletin of Siberian Medicine. 2020;19(4):14-20 (In Russ.). DOI: 10.20538/1682-0363-20204-14-20.

13. Folch J., Lees M., Sloane Stanley G. A simple method for the isolation and purification of total lipides from animal tissues. J. Biol. Chem. 1957:226:497-509.

14. Ilan E., Tirosh O., Madar Z. Triacylglycerol-mediated oxidative stress inhibits nitric oxide production in rat isolated hepatocytes. J. Nutr. 2005;135(9):2090-2095. DOI: 10.1093/jn/135.9.2090.

15. Thalmann S., Juge-Aubry C.E., Meier C.A. Explant cultures of white adipose tissue. Methods Mol. Biol. 2008;456:195-199. DOI: 10.1007/978-1-59745-245-8_14.

16. Suga H., Matsumoto D., Inoue K., Shigeura T., Eto H., Aoi N. et al. Numerical measurement of viable and nonviable adipocytes and other cellular components in aspirated fat tissue. Plast. Reconstr. Surg. 2008;122(1):103-114. DOI: 10.1097/PRS.0b013e31817742ed.

17. Steinhorn B., Sartoretto J.L., Sorrentino A., Romero N., Kalwa H., Dale Abel E. et al. Insulin-dependent metabolic and inotropic responses in the heart are modulated by hydrogen peroxide from NADPH-oxidase isoforms NOX2 and NOX. Free Radic. Biol. Med. 2017;113:16-25. DOI: 10.1016/j.freeradbiomed.2017.09.006.

18. Burgeiro A., Fuhrmann A., Cherian S., Espinoza D., Jarak I., Carvalho R.A. et al. Glucose uptake and lipid metabolism are impaired in epicardial adipose tissue from heart failure patients with or without diabetes. Am. J. Physiol. Endocrinol. Metab. 2016;310(7):E550-E564. DOI: 10.1152/ ajpendo.00384.2015.

19. Viswanadha S., Londos C. Determination of lipolysis in isolated primary adipocytes BT. Methods Mol. Biol. 2008;456:299-306. DOI: 10.1007/978-1-59745-245-8 22.

20. Do Bonfim T.H.F., Tavares R.L., de Vasconcelos M.H.A., Gouveia M., Nunes P.C., Soares N.L. et al. Potentially obesogenic diets alter metabolic and neurobehavioural parameters in Wistar rats: A comparison between two dietary models. J. Affect Disord. 2021;279:451-461. DOI: 10.1016/j.jad.2020.10.034.

21. Tran L.T., Yuen V.G., McNeill J.H. The fructose-fed rat: A review on the mechanisms of fructose-induced insulin resistance and hypertension. Mol. Cell. Biochem. 2009;332(1-2):145-159. DOI: 10.1007/s11010-0090184-4.

22. Alberti K.G.M.M., Eckel R.H., Grundy S.M., Zimmet P.Z., Cleeman J.I., Donato K.A. et al. Harmonizing the metabolic syndrome. Circulation. 2009;120(16): 1640-1645. DOI: 10.1161/CIRCULATIONAHA.109.192644.

23. Subirana I., Fitó M., Diaz O., Vila J., Francés A., Delpon E. et al. Prediction of coronary disease incidence by biomarkers of inflammation, oxidation, and metabolism. Sci. Rep. 2018;8(1):3191. DOI: 10.1038/s41598018-21482-y.

24. Rodríguez M., Pintado C., Torrillas-de la Cal R., Moltó E., Gallardo N., Andrés A. et al. Ageing alters the lipid sensing process in the hypothalamus of Wistar rats. Effect of food restriction. Nutr. Neurosci. 2021;5:115. DOI: 10.1080/1028415X.2021.1872990

\section{Information on author contributions}

Naryzhnaya N.V. - development of study concept and design, performing research study, writing the manuscript, providing rationale for the manuscript, and revision of essential intellectual content.

Birulina Y.G. - development of study concept, methodology, and model for induced metabolic syndrome and writing the manuscript.

Kurbatov B.K. - development of study design, performing research study, statistical data analysis, data interpretation, and writing the manuscript

Sirotina M.A. - performing research study and writing the manuscript.

Maslov L.N. - development of study concept, revision and editing the manuscript, providing rationale for the manuscript, revision of essential intellectual content, and final approval of the manuscript for publication.

\section{Information about the authors}

Natalia V. Naryzhnaya, Dr. Sci. (Med.)., Leading Research Scientist Laboratory of Experimental Cardiology, Cardiology Research Institute, Tomsk 
но-исследовательский институт кардиологии, Томский национальный исследовательский медицинский центр Российской академии наук. ORCID 0000-0003-2264-1928.

E-mail: natalynar@yandex.ru.

Бирулина Юлия Георгиевна, канд. биол. наук, доцент кафедры биофизики и функциональной диагностики, Сибирский государственный медицинский университет Министерства здравоохранения Российской Федерации. ORCID 0000-0003-1237-9786.

E-mail: birulina20@yandex.ru.

Курбатов Борис Константинович, младший научный сотрудник, лаборатория экспериментальной кардиологии, Научно-исследовательский институт кардиологии, Томский национальный исследовательский медицинский центр Российской академии наук. ORCID 0000-0001-9603$822 X$

E-mail: bobersanker@gmail.com.

Сиротина Мария Александровна, младший научный сотрудник, лаборатория экспериментальной кардиологии, Научно-исследовательский институт кардиологии, Томский национальный исследовательский медицинский центр Российской академии наук. ORCID 0000-0002-45020836.

\section{E-mail: sirotina_maria@mail.ru.}

Маслов Леонид Николаевич, д-р мед. наук, профессор, заведующий лабораторией экспериментальной кардиологии, Научно-исследовательский институт кардиологии, Томский национальный исследовательский медицинский центр Российской академии наук. ORCID 0000-0002-6020-1598.

E-mail: maslov@cardio-tomsk.ru.

Нарыжная Наталья Владимировна, e-mail: natalynar@yandex.ru.

Поступила 22.07.2021
National Research Medical Center, Russian Academy of Sciences. ORCID 0000-0003-2264-1928.

E-mail: natalynar@yandex.ru.

Yulia G. Birulina, Cand. Sci. (Biol.), Associate Professor, Department of Biophysics and Functional Diagnostics, Siberian State Medical University. ORCID 0000-0003-1237-9786.

E-mail: birulina20@yandex.ru.

Boris K. Kurbatov, Junior Research Scientist, Laboratory of Experimental Cardiology, Cardiology Research Institute, Tomsk National Research Medical Center, Russian Academy of Sciences. ORCID 0000-0001-9603-822X.

E-mail: bobersanker@gmail.com.

Maria A. Sirotina, Junior Research Scientist, Laboratory of Experimental Cardiology, Cardiology Research Institute, Tomsk National Research Medical Center, Russian Academy of Sciences. ORCID 0000-0002-4502-0836.

E-mail: sirotina maria@mail.ru.

Leonid N. Maslov, Dr. Sci. (Med.), Professor, Head of the Laboratory of Experimental Cardiology, Cardiology Research Institute, Tomsk National Research Medical Center, Russian Academy of Sciences. ORCID 00000002-6020-1598.

E-mail: maslov@cardio-tomsk.ru.

”' Natalia V. Naryzhnaya, e-mail: natalynar@yandex.ru.

Received July 22, 2021 